\title{
Withering the Citizen, Managing the Consumer: Complaints in Healthcare Settings
}

\author{
Judith Allsop* and Kathryn Jones ${ }^{* *}$ \\ *Professor of Health Policy, Faculty of Health and Social Care, University of Lincoln \\ E-mail: jallsop@lincoln.ac.uk \\ **Senior Research Fellow, Department of Public Policy, De Montfort University, Leicester
}

This paper considers concepts of citizenship and consumerism in light of complaints about healthcare, which have risen since the early1990s, due to a greater willingness by the healthcare user to complain, and also the reforms in complaint systems. The narrow legal model for dealing with complaints has been replaced by a managerial model based on corporate sector practice that views complaint handling as a way of retaining customers and organisational learning. The managerial model has proved difficult to embed into the English NHS and has been superposed with a centralised regulatory system that aims to manage performance while also being responsible for reviewing, complaints and being responsive to complainants. It is argued that this may have positive consequences in terms of improving healthcare quality but more negatively, the promotion of consumerism within complaints processes has led to a loss of the right to due process and public accountability.

\section{Introduction}

Making a complaint about a public service or market good is an act of individual agency, and research has demonstrated a range of motivations for making a complaint, from expressing dissatisfaction, to seeking an explanation; holding service providers to account; wanting an apology; seeking redress or pursuing compensation (Allsop and Mulcahy, 1996). Most societies and states have mechanisms to deal with complaints to provide redress as a right and on the grounds of practical politics. If a complaint escalates, there is a potential threat to social order. Felstiner, Abel and Sarat (1981) have shown how a range of factors determine the likelihood of people voicing a dissatisfaction that vary according to the particular sector. A feature of healthcare complaints is that they may be influenced by an emotional burden of harm and loss that affects families as well as individuals (Allsop, 1994; Lloyd-Bostock, 1999).

In the past, provider dominance, deferential attitudes, trust relations between doctors and patients and the narrow gateway offered by complaints systems have acted as barriers to voicing (Hirschman, 1970; Department of Health, 1995; MORI, 1995). Since the mid1990s, as part of healthcare marketisation, increased managerialism and new forms of governance (Clarke, 1997; Moran, 2002; Bevan and Hood, 2006), complaint systems have undergone a series of reforms. There has been a marked shift from a rights-based model towards a consumer model, particularly in the English NHS. It is argued that both the reforms and changes in public attitudes have created a more challenging dynamic that have brought losses as a well as gains for complainants. ${ }^{1}$ 


\section{Definitions and concepts: citizenship, consumerism and complaints}

Within the liberal and social democratic tradition, access to legal, political and finally social rights signalled an expansion of citizenship (Marshall, 1950). The creation of the welfare state brought an expansion of social rights in access to a range of services (Baldock, 2003). Those who provide public services are expected to operate in ways that are fair, impartial and related to needs that are defined in legislation and guaranteed through the democratic process. But, as Wu (2002) points out, the concept of citizenship is not fixed and can expand or contract. What are accepted as the rights of citizens is an area of contest and constantly undergoing revision. Notions of citizenship are also reflected in the claims that people make based on their sense of identity as a member of a society.

The term consumer derives from market economics rather than the sphere of state/citizen relations. People act as consumers when they pursue their own preferences - satisfying their wants in line with their ability to pay. Producers aim to both meet, and to create, demand to increase profit. Ultimately, markets are constrained by state regulation and consumers typically have recourse to civil courts to pursue their rights if they are dissatisfied. Here, the role of the state is minimal and limited to establishing a court system to provide a forum to adjudicate a dispute. In a review of the literature, Shaw and Aldridge (2003) argue that consumerism is defined in a number of ways. First, as an ideology that legitimates capitalist society where the consumer is the 'invisible hand' that shapes markets; second, as a social movement where consumer interests are represented through the formation and activity of institutions, groups or networks and, finally, as a way of life that transforms the self as people's individual sense of identity derives from what they consume (Clarke, 1997).

Within political debate, notions of citizenship and consumerism may be applied by protagonists both positively and negatively to support or critique policies or to describe behaviour. For example, a doctor may view patient demands that challenge their professional role as expert or gatekeeper, such as requesting information or querying a diagnosis as consumerist. However, others may see this as a necessary form of active partnership with a health professional. Within public policy, governments since the $1980 \mathrm{~s}$ have couched health reforms in terms of promoting the patient and consumer interest as a counter force to provider monopolies. The rhetoric of consumer empowerment has been used to justify reform and to construct the image of an active consumer within a responsive and participatory process (Newman and Vidler, 2006). It would be surprising if this sustained policy drive had not had an effect on the behaviour of patients and carers, and there is evidence of a rise in the numbers of complaints made by healthcare users as well as of increasing group formation to promote and represent the interests of people with particular conditions in healthcare (Allsop et al., 2004).

\section{Patient and carer activism}

The data available suggest that the numbers of complaints began to rise in the early $1990 \mathrm{~s}$ and subsequently have been on an upward trend. Opinion studies invariably show high levels of public satisfaction with the NHS but in analyzing British Social Attitudes survey results between 1983 and 2001, Taylor-Gooby and Hastie (2003) show that dissatisfaction with the NHS has tended to increase, most markedly for in-patient care with resourcelinked or organizational areas causing most concern. Data also indicate that younger 
Table 1 Complaints about healthcare in England, 1997/8-2004/5

\begin{tabular}{llll}
\hline \hline Complaint body & $1991 / 2$ & $1997 / 8$ & $2004 / 5$ \\
\hline $\begin{array}{l}\text { Complaints received by Family Health } \\
\quad \text { Services: Medical (England) }\end{array}$ & not available & not available & 35,431 \\
$\begin{array}{l}\text { Clinical Complaints received by Hospitals } \\
\quad \text { England) }\end{array}$ & 51,511 & 59,588 & 65,346 \\
$\begin{array}{l}\text { Complaints received by the General Medical } \\
\quad \text { Council (UK) }\end{array}$ & 1087 & 3,066 & $4,452^{*}$ \\
Health Service Ombudsman: cases (England) & 972 & 2,660 & 2,478 \\
\hline \hline
\end{tabular}

Note:*Complaints/enquiries received: http://www.gmc-uk.org/about/council/papers/2006_07/4a\% 20-\%20Annex\%20C.pdf

Source: Department of Health dataset KO41a, KO41b; GMC; Health Service Ombudsman.

people were more likely to report dissatisfaction, and those in higher income groups more likely to point to a shortfall of resources and less likely to criticise staff attitudes. The national surveys of people having treatment for cancer and heart disease, provide a more nuanced picture of peoples' views. They indicate greater dissatisfaction than general surveys and the aspects of care where people are less satisfied (Allsop, 2006).

When seen in relation to the number of healthcare transactions, the number of complaints is small. However, in a household survey undertaken in 1996, Mulcahy and Tritter (1998) found that of those who said they had been dissatisfied with the healthcare they had received, only a small minority, about one in ten, complained. Data on the incidence of complaints shown in Table 1 show that the number of complaints made to various health regulators has been on a rising trend. Complaints to NHS trusts, to the General Medical Council and the Health Service Ombudsman, all gateways for the healthcare user, have increased since the early 1990s with only the latter showing signs of levelling off.

The data suggest that healthcare users have higher expectations and are more critical of the care received. MORI data from the mid-1990s shows that the public were critical of the existing complaint systems, which they said were difficult to access and staff acted defensively. It can be argued that greater activism on the part of healthcare users, and the actions of governments through marketisation and reforms to complaint systems have encouraged people to voice their concerns. It is also argued that reforms reflect a shift of focus from citizen rights to satisfying the health consumer. The rise in complaints may be also in part be an artefact based on changing definitions and recording. Prior to the 1990s, in order to be recorded, public sector complaints generally had to take written form and contain an allegation that warranted further investigation. This offered scope for discretion and narrowed the gateway for making a complaint. In contrast, one current definition is that a complaint is 'any written or spoken expression of dissatisfaction with a service' (NAO, 2005: 11). This broad definition itself reflects private sector terminology, which aims to anticipate, track and act on consumer concerns. While health service providers and professionals have been encouraged to use this definition, for practical reasons it is unlikely that they do so. Nevertheless, publicity about how to make a complaint and greater awareness of how to do it is part of the explanation for the rise in complaints. 
In order to demonstrate the shift from seeing complainants as citizens entering into a dispute about a state-provided service towards treating then as consumers, different models of complaint systems, their rationale and how these have been applied in the NHS are outlined. Most complaint systems have two stages: an initial investigation by a provider, the first stage, and a second stage that offers a review or appeal of the first stage decision.

\section{Models of complaint system and their application in the NHS}

The legal model

At the end of the nineteenth century and the emergence of the welfare state, the right to make a complaint about a state-provided service was regarded as an aspect of citizenship. A matter of concern for legislators was the right of the citizen to raise a complaint when the state itself was providing the service: that is how to maintain a separation of powers. The remedy was seen as a tribunal independent of the organisation based on legal principles and procedures to ensure a fair process. Grievance procedures may vary from the most formal adjudicatory or inquisitorial process to informal tribunals, panels or committees or even rely on a report of an investigation by a single investigator as in Ombudsman systems. Grievance handlers are able to fashion solutions, but in highly defined and limited ways. A common denominator is that all issues are initially presented and a decision made based on the language of individual rights, and the duties of the parties as members of society - as citizens. This limits what the decision taker(s) can see and do but accords priority to procedural fairness and impartiality. The aim is to set the boundaries of what is acceptable behaviour and to allow for the ritualistic closure of a dispute.

The Franks Committee (1957) reiterated the benefits of tribunals and outlined the principles on which they should be based as a way of protecting the citizen against the administrative state. They should be independent, accessible, prompt, expert, informal and cheap and incorporate the principles of openness, fairness and impartiality. Tribunals offered a speedier alternative to the courts, combining the advantages of due process with the opportunity of a full discussion in an informal atmosphere. In a recent review of tribunals, Sir Andrew Legatt, while endorsing the system, commented on the difficulty of being seen as independent when run by the department providing the service: openness and due process were therefore of utmost importance (Legatt, 2001).

Tribunals in healthcare have a history dating back to the 1911 National Insurance Act (Klein, 1973) when a complaint could be made by an insured person about the first-line care provided by a panel doctor, to a third party, thus raising a criticism of a partially state-funded service The process also allowed the insurance committees to check on the work of the panel doctors. Following the $1946 \mathrm{NHS}$ Act, this system was incorporated into the health service for family practitioners but not hospital doctors. This system remained in place until 1996 with, from 1974, Community Health Councils providing a source of independent advice and support for those wishing to complain, thus strengthening their citizen rights.

\section{The bureaucratic model}

In some public services, complaints are handled by the government department itself. In this case, grievance procedures are based on the state's duty to provide a service, but there 
is no separation of investigative powers. From a legal perspective, the bureaucratic model is perceived to lack transparency and independence. Decision-making powers may be exercised in an arbitary manner. Sociological studies of bureaucratic organizations have demonstrated a tendency for officials to support the interests of their organisation (Sennett, 2003) and have demonstrated conscious or unconscious bias in the use of discretion (Serber, 1980). The initial stage of any complaint procedure typically involves a screening process, which tends to be hidden from view. In recent times, the final Shipman report was sharply critical of the informal screening of complaints (now reformed) received by the General Medical Council (Shipman Inquiry, 2004).

\section{The professional model}

Grievance systems to handle complaints against professionals form a third type. Historically, the medical profession in particular has been successful in their claim to have the expertise and authority make judgements about the work of their colleagues. In the case of complaints, judgments about whether clinical work has reached a reasonable standard have been based on what can be expected of an ordinary practitioner within a particular field of medicine. Often, though not always, such professional judgements have been made in settings that are closed to public view. This has been justified in terms of the threat to a professional's livelihood in a situation where a complaint might prove to be unfounded, or of a minor nature (see Franks Committee, 1957). The credibility of such systems depends on the extent of public trust in self-regulation. They are often poorly understood by the public, seen as biased by complainants, thus exacerbating a sense of grievance (Allsop, 2006).

Within the NHS, complaint systems have been shaped by the interests of the medical profession. In primary care, although the service committees established in 1948 took a tribunal form with a balance of lay and professional members and had a lay chair, the process was not open to public scrutiny and anonymised reports were available only to the parties. Hospital boards were not required to have a complaint system at all until 1985, despite the Davis Committee (DHSS, 1973) report, recommending a hospital complaint system. Reforms, when they came, depended on the success of a private members bill. This required hospitals to establish a complaints procedure but this was an internal process; the form it took was discretionary and moreover a distinction was made between 'clinical and non-clinical' complaints. Complaints about doctors followed an elaborate, medically dominated and closed process, culminating in a final decision on appeal to the regional medical officer. Complainants were rarely interviewed and were informed of outcomes, but had no right of access to reports (Mulcahy, 2003).

\section{The managerial model}

The managerial model for complaint handling aims to resolve complaints to the satisfaction of the consumer to retain customer loyalty. Initially promoted for private sector business in the United States, these ideas influenced public service reforms in the 1990s in the UK. Goodman (2006) in a recent review summarises the management literature, which is based on the belief that every grievance offers a chance to correct a process and to educate the customer. Analyzing trends provides valuable information on 
what consumers want, while training staff to avoid adversarial situations and the offer of redress for dissatisfaction caused can be justified in terms of future profit. Prime Minister John Major's charters of the early 1990s (Cabinet Office, 1991) can be seen in retrospect as transitional documents. They used the language of citizenship in terms of stating patient entitlements, such as access to services, to be seen within a certain time period and the right to complain, but were in practice geared to enhancing managerial performance. The targets set could be monitored and audited by government bodies - a device later developed under Labour governments.

In 1996 following the Department of Health report, 'Being heard' (DH, 1995), a unified complaint system was introduced across all English NHS trusts and GP practices. In England, the aim of the reforms was to follow corporate sector practice in aiming to develop a culture in which health care staff responded to, and tried to resolve, complaints as they occurred. In what was referred to as a first stage, complaints that were not resolved were referred to the complaints department where a manager set up and oversaw the subsequent resolution process and analyzed trends. If complainants were not satisfied, they could ask for a review by an independent lay panel. Although there was little guidance available, panels generally followed an inquisitorial process by questioning the parties to determine what had gone wrong. Recommendations on the action that should be taken to improve practice were made to the trust board. The reforms were supported by medical professional associations, possibly because they were seen to avoid blame being placed on individual doctors. Rather, the organization was held responsible for poor practice.

Arrangements for this second stage reflected an uneasy compromise between a complainant's right to an independent, fair and impartial review and managerial principles that emphasised resolution and learning. The tension was evident in the role of the convener, a member of the trust board whose role was to decide whether there should be a review. Three separate evaluation studies of the reforms showed that neither conveners themselves, nor other participants in the process, saw them as independent of the trust (Kyffin et al., 1997; Wallace and Mulcahy, 1999; Department of Health, 2001). Other problems identified were considerable variability in practice across trusts; a failure on the part of trusts to implement panel recommendations and the shortcomings of the process when applied to general practice where patients feared repercussions if they made a complaint. The Health Service Ombudsman, who has powers to investigate complaints on appeal has voiced similar concerns. Recent reports have been critical of managers paying more attention to process than content, an over-obsession with time limits at the expense of proper investigation, a lack of training for staff and the low priority given to complaints by senior management (Health Service Ombudsman, 2005).

On the more positive side, reforms to complaint system have made it easier for people to make a complaint. The requirement for each NHS trust to set up a Patient Advice and Liaison Service (PALS) in 2002, made an important contribution to dealing with patients' concerns at an early stage and by providing information and support, even though it was not independent of the trust (Abbott et al., 2006).

\section{The regulatory model}

In 2004 in England, the complaints system was again reformed introducing a system of centralised top-down regulation to ensure that managers adopted consumerist practice: 
in this instance through oversight by the audit and inspection body for England, the Healthcare Commission. Non-governmental, arms-length regulatory bodies, have been widely used under both Conservative and Labour governments so that lower-level bodies conform to standards and targets set centrally. This way of governing public sector institutions at a distance has been theorised in different ways and its consequences assessed by a number of scholars; for example, Power (1997), Moran (2002) and Bevan and Hood (2006).

The Healthcare Commission is both regulator and adjudicator as it became responsible for the second stage of the complaint process; that is, reviewing complaints where complainants remain dissatisfied with the trust's response. In stating its objectives in introducing reforms, the Department of Health (2004) emphasized the importance of independence, consistency and speed. Although initially, the plan was to retain lay panel reviews operating under the aegis of the Commission, this was abandoned in 2006, so that reviews are carried out in-house by Health Commission staff (Department of Health, 2006). From Health Commission reports available on the internet, it appears that if, following an initial screening process, the Commission takes on an investigation of a complaint, a staff team will review the complaint file and collect further information if necessary, seeking further expert opinion. During the process, the complainant is asked what they wish to achieve from the process. The review of cases investigated concludes with a report with recommendations written to a standardised format, which is sent to the complainant and the trust. If the complaint is sustained, a form of redress may be suggested to the trust, such as an explanation, an apology, possibly financial recompense and suggestions made for changes in trust practice.

In a recent report, 'Spotlight on complaints' (Healthcare Commission, 2007) the Commission reviews its work since 2004 and by implication provides a rationale for the increasing emphasis on improving complaint handling in trusts, which has proved to be expectedly burdensome. First, the volume requests for review far exceeded expectations, running at around 8,000 per year as compared to just over 3,000 per year under the previous system. In consequence, complaints now absorb 20 per cent of the Healthcare Commission's overall budget and 150 staff are employed at a cost of $£ 10$ million per annum. Second, a third of requests for review are returned to trusts, as the initial investigation was inadequate. Third, in view of the volume of cases, a highly structured approach is taken to case assessment and management. Complaints assessed as posing 'low or medium' risk, are outsourced to a private sector company to process. How risk is defined is not clear, but the choice of terminology supports Power's (1997) argument that regulation should be seen in terms of risk management. Within the Commission, a core central staff supervise closely knit teams reminiscent of what Sennett (2003) refers to as a squat rather than a hierarchical bureaucracy. It is also worth noting that the support and advocacy service formerly provided by Community Health Councils in each locality, now called the Independent Complaints and Advocacy Service (ICAS), has also been subject to a contracting process. Initially, Citizen's Advice held the contract in six out of nine regions but has been replaced by a number of other contractors.

One advantage of centralizing complaint review is that the Commission has been able to identify the main causes for complaint by theme and sector. The two top categories out of ten are safety of clinical practices (22 per cent); poor communication from providers to patients or carers or a lack of information (16 per cent). The remaining eight categories each make up 5 per cent of the total or less. For acute trusts, around 30 per cent of 
complaints are associated with the death of a patient. In relation to general practice, delays in diagnosis and referral, the quality of out-of-hours services and the removal of a patient from a GP list are common problems. Some of these issues have been identified by the Health Service Ombudsman reports, but as the regulator in England, the Commission has the leverage to adopt name and shame strategies to improve practice. Spotlight on Complaints identifies the worst and best trusts in terms of requests for review and promises to use information from reviews to sharpen on-site audit and inspection. More positively, the Commission has held training events and promises future guidance on good practice. It has also carried out a survey of the complainants' opinions of the review process finding that 71 per cent of those taking part found the process fair, independent and helpful - by deduction, 29 per cent presumably did not. Too little information is provided to assess the survey results. Complainants are not asked to evaluate the process on receiving the report.

\section{Discussion and conclusion}

From the review of models of complaint systems and their application, it is apparent that opportunities for voicing are shaped by social arrangements and these reflect particular values, political interests and power relations. These are expressed in different forms of discourse that reflect the preoccupations of the time: the terms 'citizen' and 'consumer' are symbols of belief systems but also shape the institutions that provide opportunities for people who are dissatisfied to voice their concerns, affect the degree of control they will have over the process and what redress they can obtain.

In legally based approaches, the state establishes a neutral and independent forum so that people can challenge a service run by the state itself. The processes used are knowable and outcomes, technically at least, fair between claimants as they are rule based. Since the 1990s, as the state has increasingly decoupled itself from direct service provision, managing dissatisfaction and disputes has been devolved to lower-level providers and become more ostensibly consumerist. This had some advantages for the service user. In the past, despite the rhetoric of citizenship, complaint systems in health care took a hybrid form and were often geared to protecting the interests of providers. The gateway to complaining was narrow and access to a neutral forum limited to the few more serious cases. This could, in itself, be taken as a denial of citizenship.

Although they were subsequently found to have weaknesses, the 1996 reforms widened the gateway and for the first time offered a unified complaint system across the NHS. The aims were two-fold: on the one hand to encourage a more critical and active consumer to whom managers were expected to respond by resolving issues and offering 'soft solutions', and on the other to enable lessons to be learnt by providers. Lay panels were an acknowledgment that not all complaints can be resolved and that further information might be required by questioning the parties, adjudicating the dispute and providing an opportunity for ritual closure.

The solution to the weaknesses identified has been to centralise the review stage in the Healthcare Commission. But, this has revealed that although most complaints are being resolved by trusts, requests for review have soared since the Health Commission took over. It is not known whether requests for review are driven by complainants wanting yet another opportunity to air their dissatisfaction, whether the cases going for review are intrinsically more complex and difficult with a high emotional content or whether they 
are a consequence of poor practice. It is likely that a combination of these factors has led to the increase, which has had cost implications. It is not known either why lay panels, which introduced an element of independence, were abandoned. What is apparent is that priority is now given to embedding more consumerist practices in trusts in the way they respond to complaints. From the vantage point of a central agency, good practice can be identified and disseminated, common causes for complaint identified and decisive action taken if poor professional standards are identified through referral to the appropriate body. However, health providers have strong incentives to resist putting resources into complaint handling, if this interferes with what they consider as their core business, and may also be defensive of criticism of both staff and systems. As others have shown, competitive, performance-driven environments in the process of rapid change reduce trust relations and encourage gaming, concealment and defensiveness, particularly where services rely on professional expertise (Bevan and Hood, 2006).

From the perspective of those who have made a request for a review, what evidence there is indicates that making a complaint remains lengthy and onerous (Citizens Advice, 2005; Head, 2006). The Health Commission process is largely paper-based with little opportunity for complainants to challenge the accounts given by others. Research and commentary on the social and psycho-dynamics of complaints indicate that making a complaint often involves families and kin networks, particularly in more complex and serious cases (Allsop, 1994; Lloyd-Bostock, 1999). Holding people to account, disclosure, being given an explanation and having an opportunity for forgiveness through personal interaction with those responsible can be critical elements in resolution but do not currently feature in the Health Commission's repertoire (Robinson, 2005).

In addition, there are weaknesses in current arrangements from the perspective of public accountability. There is no information on the decision rules, processes and the reasoning behind decisions taken by the Commission in screening or disposal. Spotlight on Complaints, the fullest report on the Commission's work, gives examples of cases but there is insufficient detail to deduce the reasoning behind decisions. The costs devoted to the new process justify a greater degree of public accountability. To date there has been no outside scrutiny of the reforms in England, although this is planned. A comparison between the complaint systems in different nations across the UK would make a worthwhile topic for research to assess relative satisfaction and outcomes - in the case of Wales Community Health Councils have been retained and in Scotland only the Health Ombudsman reviews complaints. In short, in moving towards a consumerist model, some of the guarantees of openness, independence and fairplay that protect the citizen seem to have been lost.

\section{Note}

1 Scotland and Wales have different systems for complaints handling. For example Wales retained Community Health Councils following their abolition in England in 2000/01. In Scotland, the only form of review of local-level complaint handling is via the Health Ombudsman (see Gulland, 2006).

\section{References}

Abbot, S., Meyer, J., Bentley, J. and Lanceley, J. (2006), 'Patient advice and liaison services: strengthening the voice of the service user in health-care', Health Expectations, 9, 2, 138-147.

Allsop, J. (1994), 'Two sides to every story: complainants' and doctors' perspectives in disputes about medical care in a general practice setting', Law and Policy, 16, 2, 149-184. 
Allsop, J. (2006), 'Regaining trust in medicine: professional strategies', Current Sociology, 54, 4, 621636.

Allsop, J., Jones, K. and Baggott, R. (2004), 'Health consumer groups: a new social movement?', Sociology of Health and IIlness, 26, 6, 737-756.

Allsop, J. and Mulcahy, L. (1996), Regulating Medical Work, Buckingham: Open University Press.

Baldock, J. (2003), 'On being a welfare consumer in a consumer society', Social Policy and Society, 2, 1, 65-71.

Bevan, G. and Hood, C. (2006), 'What's measured is what matters: targets and gaming in the English public health care system', Public Administration, 84, 3, 517-538.

Cabinet Office (1991), Citizen's Charter: Raising the Standard, London: HMSO.

Cabinet Office Complaints Task Force (1995), Putting Things Right, Main Report, London, HMSO.

Citizen's Advice Bureau (2005), 'The pain of complaining: CAB/ICAS evidence of the NHS complaints procedure', unpublished report.

Clarke, J. (1997), 'Capturing the customer: consumerism and social welfare', Self, Agency and Society, 1, 1, 55-73.

Department of Health (1995), 'Being heard: the report of a review committee on NHS complaints procedures', Department of Health, London.

Department of Health (2001), 'Handling complaints: monitoring the NHS Complaints Procedures, England 2000-1', Department of Health, London.

Department of Health (2004), The National Health Service (Complaints) Regulations, SI 2004 No. 1768, Department of Health, London.

Department of Health (2006), The National Health Service (Complaints) Amendment Regulations, SI 2006 No. 2084, Department of Health, London.

DHSS (Department of Health and Social Security) (1973), 'Report of the Committee on the Hospital Complaints Procedures', DHSS, London.

Felstiner, W.L.F., Abel, R.L. and Sarat, A. (1980-1), 'The emergence and transformation of disputes: naming, blaming, claiming', Law and Society Review, 15, 3-4, 631-654.

Franks Committee (1957), Committee on Administrative Tribunals and Inquiries, Cmnd.218 (Chair: Sir Oliver Franks), HMSO, London.

Goodman, J. (2006), 'Manage complaints to increase loyalty', Quality Progress, 39, 2, $28-34$.

Gulland, J. (2006), 'Second tier reviews of complaints in health and social care', Heath and Social Care in the Community, 14, 3, 206-214.

Head, S. (2006), 'Got a pain? Don't complain', Society Guardian, 9 May, at www.society.guardian.co.uk [accessed 10/5/2006].

Health Service Ombudsman (2005), 'Making things better?', A report on the reform of the NHS complaints procedure in England, HC 415, London.

Healthcare Commission (2005), Meeting of the Healthcare Commission, 23 June 2005 Report from the Head of Complaints, Healthcare Commission, London.

Healthcare Commission (2007), 'Spotlight on complaints', Report on the Second-Stage Complaints about the NHS in England, Healthcare Commission, London.

Hirschman, A.O. (1970), Exit, Voice and Loyalty, Cambridge, MA: Harvard University Press.

Klein, R. (1973), Complainants against Doctors, London: Charles Knight.

Kyffin, R., Cook, G. and Jones, M. (1997), 'Complaints handling and monitoring in the NHS: a study of 12 trusts in the north west region', University of Liverpool Institute of Medicine Law and Bioethics, Liverpool.

Leggatt, A. (2001), Tribunal for users - One system, One Service: Report of the Review of Tribunals (Sir Andrew Leggatt), London: Lord Chancellor's Department.

Lloyd-Bostock, S. (1999), 'The social psychology of making and responding to hospital complaining and claiming as social processes', in M. Rosenthal, L. Mulcahy, and S. Lloyd-Bostock (eds), Medical Mishaps: Pieces of the Puzzle, Buckingham: Open University Press. 
Marshall, T.H. (1950), Citizenship and Social Class and Other Essays, Cambridge: Cambridge University Press.

Moran, M. (2002), 'Review article: understanding the regulatory state', British Journal of Political Science, $32,2,391-413$.

MORI (1995), Attitudes Towards and Experience of Complaints Systems, London: HMSO.

Mulcahy, L. (2003), Disputing Doctors: The Socio-Legal Dynamics of Complaints about Medical Care, Maidenhead: Open University Press.

Mulcahy, L. and Tritter, J. (1998), 'Pathways, pyramids and icebergs? Mapping the links between dissatisfaction and complaints', Sociology of Health and Illness, 20, 6, 825-847.

National Audit Office (2005), 'Citizen redress: what citizens can do if things go wrong with public services', Report by the Comptroller and Auditor General, HC 21 Session 2004/5, London, NAO.

Newman, J. and Vidler, E. (2006), 'Discriminating customers, responsible patients, empowered users: consumerism and the modernisation of health care', International Social Policy, 35, 2, 193-209.

Power, M. (1997), Audit Society: The Rituals of Verification, Oxford: Oxford University Press.

Robinson, J. (2005), 'Complaints and forgiveness: the healing process', British Journal of Midwifery, 13, 4, 243.

Sennett, R. (2003), Respect: The Formation of Character in an Age of Inequality, Harmonsworth: Penguin.

Serber, D. (1980), 'Resolution or rhetoric: managing complaints in the California Department of Insurance', in R. Nader, No Access to Law: Alternatives to the American Judicial System, London: Academic Press.

Shaw, I. and Aldridge, A. (2003), 'Consumerism, health and social order', Social Policy and Society, 2, 1, $35-43$.

Shipman Inquiry (2004), 'Independent public inquiry into the issues arising from the case of Harold Frederick Shipman', Fifth Report, Chair Dame Janet Smith, The Stationery Office, London.

Taylor-Gooby, P. and Hastie, C. (2003), 'Dissatisfaction with the NHS: too few resources or the New Consumerism?', Political Quarterly, 74, 2, 233-240.

Wallace, H. and Mulcahy, L. (1999), Cause for Complaint: An Evaluation the Effectiveness of the NHS Complaints Procedure, London: The Public Law Project.

Wu, A.S. (2002), 'Beyond the paradoxical conception of "Civil Society without Citizenship"', International Sociology, 17, 4, 529-548. 